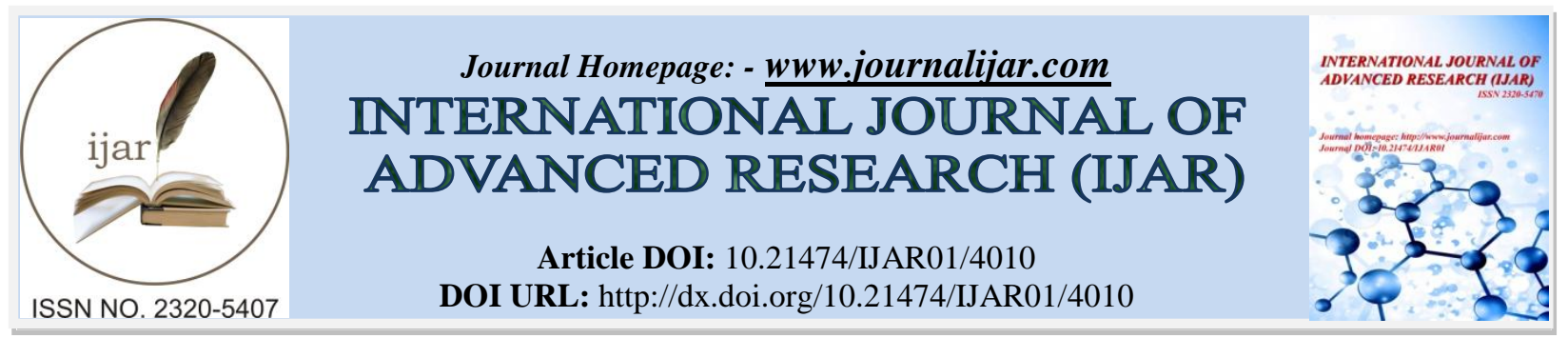

RESEARCH ARTICLE

\title{
OSTEONECROSIS OF FEMORAL HEAD: OUTCOME OF CORE DECOMPRESSION WITH CANCELLOUS BONE GRAFTING.
}

\author{
Dr Arvind Kumar, Dr Sudhirkumar Rawat, Dr Parth Deshmukh, Dr Ajay Mandloi, Dr Jainish Patel, Dr \\ Amit Patel, Dr Anirudh Bansal and Dr Vikramjit Singh Baath. \\ Department of orthopaedics, SBKS medical college and research centre, Pipariya, Vadodara, Gujarat.
}

\section{Manuscript Info}

Manuscript History

Received: 23 February 2017

Final Accepted: 09 March 2017

Published: April 2017

Key words:-

Avascular Necrosis (AVN), Femoral Head, Core Decompression, cancellous Bone graft, Harris Hip Score (HHS), Visual analog pain score (VAS), Alendronate.

\begin{abstract}
Background: Osteonecrosis of femoral head results in femoral head collapse in $75-85 \%$ of untreated patients. It is debilitating diseases which frequently progressing to femoral head collapse and secondary osteoarthritis of hip joint. Treatment of choice is total hip replacement in end stage of diseases. But it commonly affects males between age group of 20-40 years. Hence in younger age group patients total hip joint replacement is not ideal option in early stages of osteonecrosis. So there was need of study the efficacy of decompression of femoral head and bone grafting with cancellous bone.

Material and Method: A prospective analytic study of 70 hips in 50 cases was done. 50 patients with osteonecrosis of femoral head treated between 2014 - 2016. All patients were evaluated clinically and radiologically. Selected cases were belonging to stage 1 and stage 2 modified Ficat and Arlet classification. We performed core decompression and cancellous bone grafting. Outcome was assed clinically with Harris hip score (HHS), Visual analogue score (VAS), and radiologically by $\mathrm{x}$ rays and MRI. MRI was done preoperatively to confirm the diagnosis and 3, 6, and 12 months post operatively for assessment of healing.

Results: Outcome was assed clinically with Harris hip score (HHS) and Visual analogue score (VAS). In our series of 70 hips in 50 cases, 22 hips had excellent, 28 hips had good outcome, 8 fair and 12 poor. All excellent and good patients returned to their prior activity. Progressive pain and progression of collapse seen in 20 patients having poor and fair results and they eventually ended up in total hip replacement.

Conclusion: We found that use of cancellous bone graft in the management of osteonecrosis of femoral head proved to be an excellent treatment modality. Procedure provides decompression of the avascular lesion, removal of necrotic bone and elevation of articular surface of head through core track
\end{abstract}

Copy Right, IJAR, 2017,. All rights reserved.

\section{Introduction:-}

Osteonecrosis of femoral head is debilitatng diseases. Etiology is unknown. However it is thought to be multifactorial. It results in femoral head collapse in $75-85 \%$ of untreated patients. Recent trend in treatment of 
osteonecrosis of femoral head aim is to preserve the joint in the early stages (Modified Ficat and Arlet classicfication) FAS 1, 2 and to delay the replacement surgery in advanced cases.

Principle of core decompression is it relives intraosseous pressure caused by venous congestion, allowing improved vascularity and possibly slows down the progression of the avascular necrosis of femoral head. This study describes early results of treatment of avascular necrosis of femoral head by decompression and cancellous bone grafting.

\section{Material and Methods:-}

A prospective analytic interventional study was carried out from 2014 to 2016 in our institution, Department of Orthopaedics SBKS medical college and Dhiraj general hospital Pipariya, Vadodara, Gujarat .Total 50 patients (70 hips) in which diagnosis of osteonecrosis of femoral head was made clinical examination was performed in all patients revealed pain with range motion and ambulation. Limitation of internal rotation in both flexion and extension were found with passive internal rotation and extension being particularly painful. Further evaluation was done with plain $\mathrm{x}$ rays and MRI scan. Study group includes 50 patients. 35 males and 15 females.20 patients (40 hips) with bilateral involvement and 30 patients with unilateral involvement. Bilaterally affected patients were operated in same sitting. Patients were staged according to modified ficat and arlet classification. All the patients belongs to stge 1 and stage 2 of femoral head osteonecrosis. The age of patients in study group ranged from 20 to 45 years the mean age was 32.5 years.

\section{Operative Procedure:-}

Under general anesthesia or spinal anesthesia, supine position on standard operating table. Percutaneous two guide wire was passed under guidance of image intensifier. Tip of guide wire was directed into the centre of most necrosed portion of the head of femur. After achieving proper insertion of guide wires in necrotic area of femoral head it was confirmed on AP and lateral view on image intensifier, then 3-5 cm incision was taken on base of the guide wire, fascia lata is splited in line of incision. Then guide wire over reamed with $6 \mathrm{~mm}$ reamer. Then all necrotic material was qurrated out with qurret. Depressed articular margin was elevated and Cancellous bone grafting was inserted in the both tracts. Then wound was closed in layers.

Cancellous bone graft was taken from anterior iliac crest. Under general or spinal anaesthesia . A 3 to $4 \mathrm{~cm}$ incision is located over the iliac creast (contralateral side in unilateral cases) posterior to the ASIS to protect the lateral cutaneous nerve. After incision the skin and subcutaneous layers, sharply incise the white facial confluence of gluteal/tensor and abdominal musculature over the iliac crest and the periosteum. Periosteum is elevated with periosteal elevator and cancellous graft is harvested with bon gauge. And wound is closed layer wise.

\section{Post Operative Cares:-}

For the ASIS graft site compression bandage was applied until removal of sutures. Active range of motion exercise of knee and ankle started during the immediate postoperative period. partial weight bearing started after 6 weeks post operatively. Full weight bearing with walker started after 3 months. We have given alendronate to all patients post operatively.

\section{Evaluation:-}

Patients were followed up at 1 month, 3 months 6 months 1 year and one and half years and 2 years. Evaluation of the patients regards to pain, distance walk with or without support, climbing of stairs, sitting, squatting and clinically examined range of movements of hip using Harris hip scoring system, according to which the score $<70$ was poor, 70-79-fair, 80-89-good, 90-100 excellent. Follow up check x ray were taken.

\section{Results:-}

The patients had good clinical improvement with relief of pain and range of motion improvements. In unilateral case left hip was involved in 18 cases and 12 hips involved in right. Bilateral involvement is seen in 20 cases (40 hips). 40 hips belonged to stage 1 and 30 hips were classified in to stage 2(stage 2A-20 


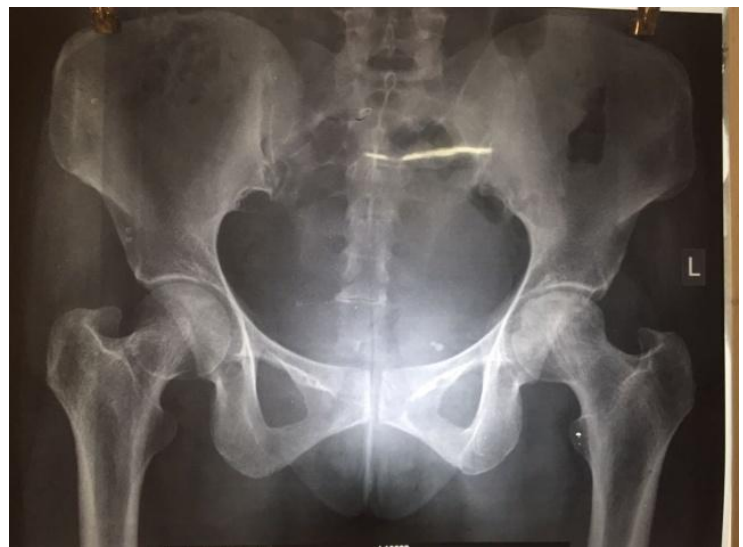

Pre-op x ray

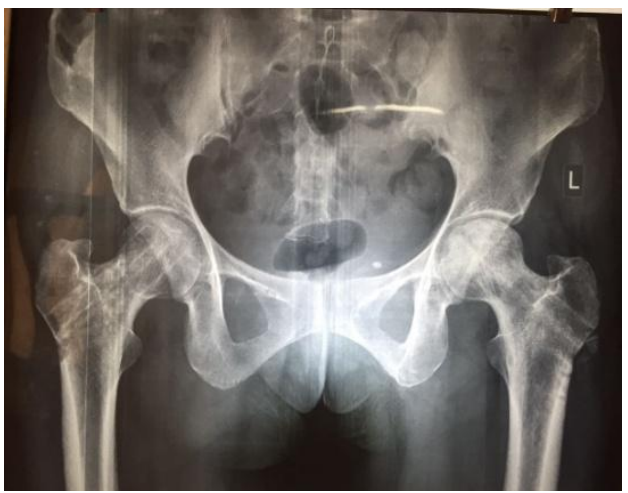

Follow up on 2 months

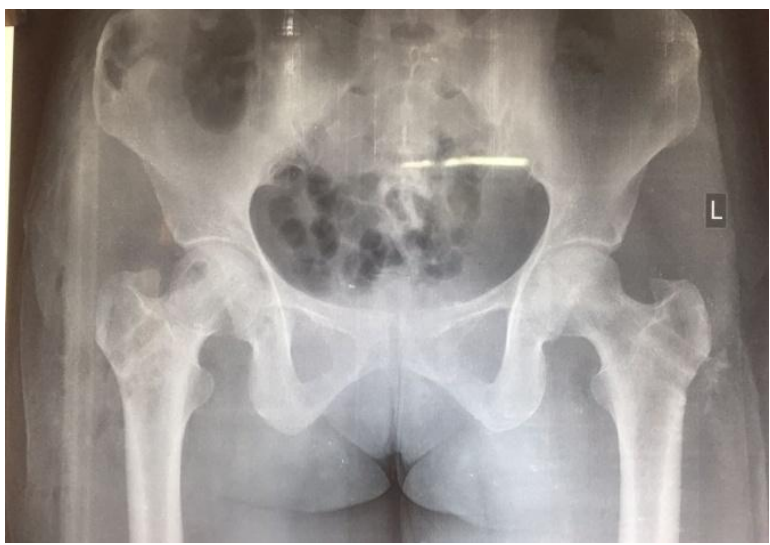

post op x ray

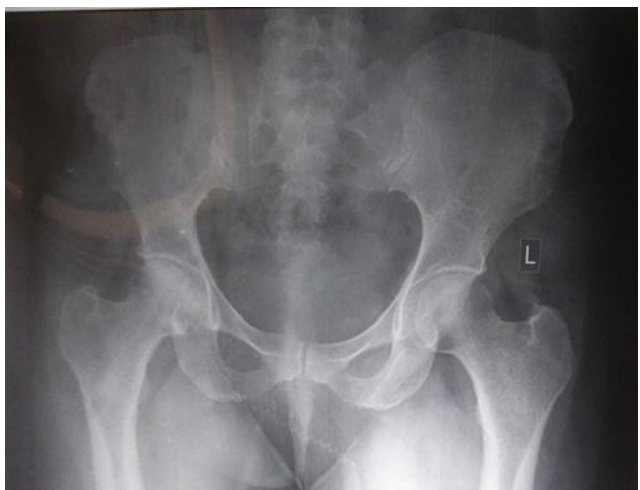

Follow up on 6 months

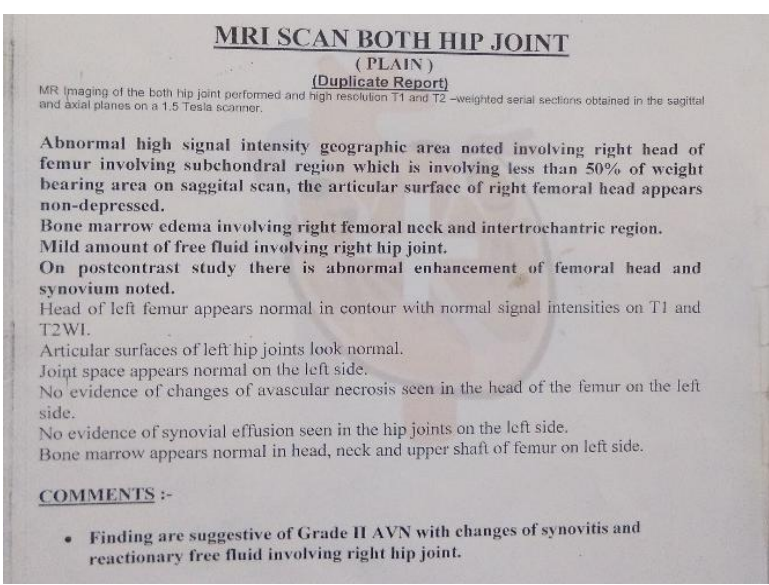

Pre op MRI scan

Follow up movement

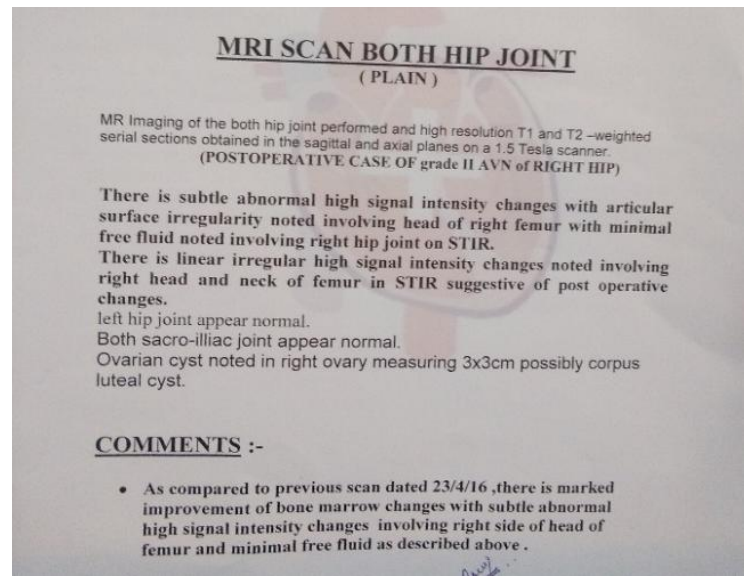

on follow up 6 month MRI scan 


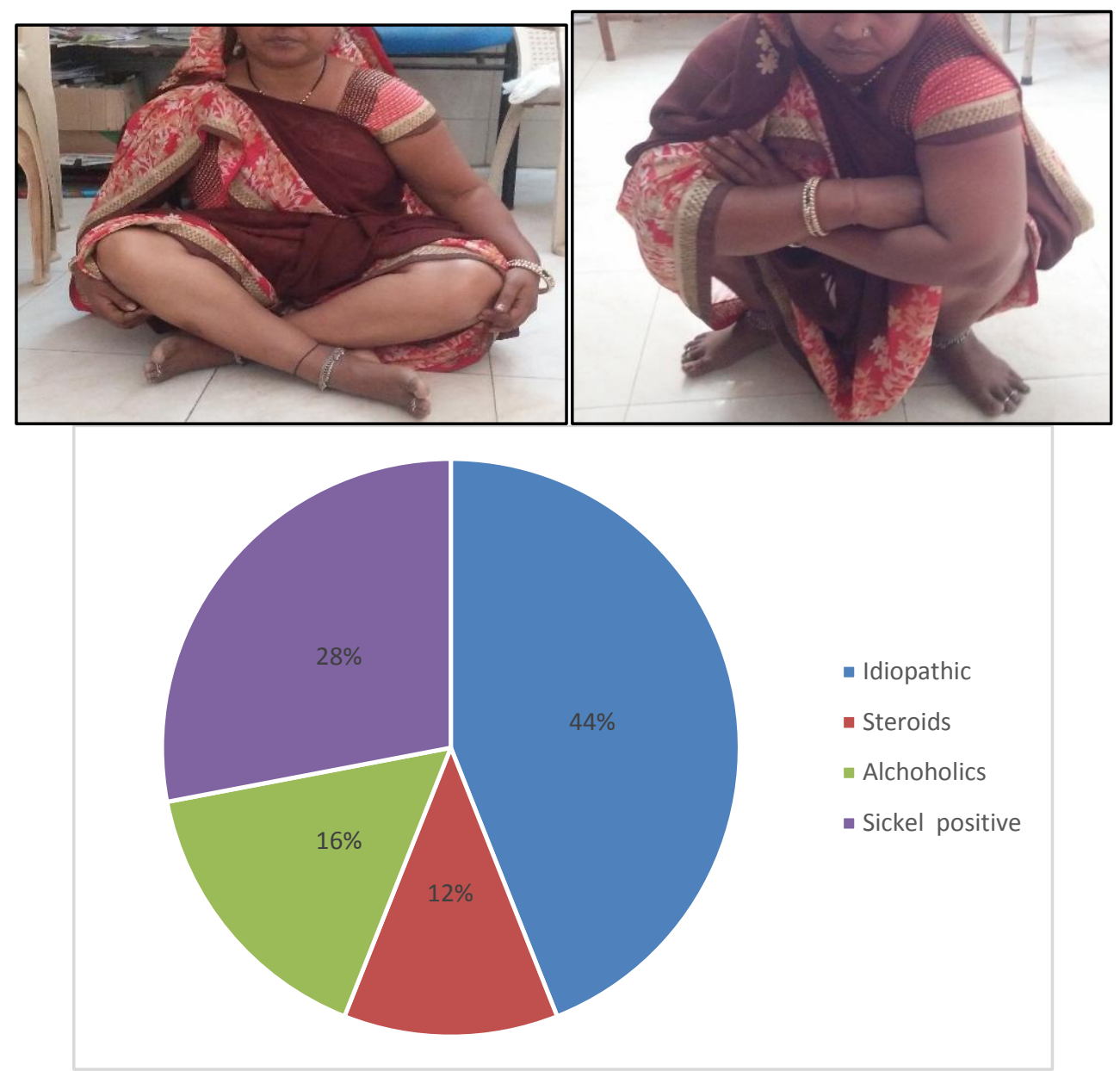

and stage 2B -10). Radiological progression and increased pain was seen in 20 patients which eventually ended up in total hip replacement at the end of follow up period.

\section{Discussion:-}

This study was performed on 70 hips of 50 cases, 35 males and 15 females, 30 cases had unilateral AVN and rest 20 had bilateral AVN. Modified Ficat and Arlet classification was used. stage 1- 40 hips, stage -2A 20 hips and stage 2B 10 hips. 22 patients having AVN had idiopathic cause, 6 patients had history of drug intake, 8 patients were alchoholics and 14 patients were sickle positive.

Treating ischemia of femoral head has become more common since many of the cases are detected in early stage. Early diagnosis before the appearance of radiological changes is very important of avascular necrosis. Diagnosis is based on clinical examination, bone scan, CT scan and MRI. X-ray is of very limited significance in early stage of the disease.MRI has dramatically improved the diagnosis of avascular necrosis, especially in the early stages when there are only bone marrow changes

Core decompression reduces the symptoms of pre collapse stage of ischemic necrosis because of reduction of pressure in compartment. There is no significant role of conservative management in osteoporosis of femoral head. The ideal treatment modality should be simple, reproducible and withlow morbidity and mortality.the main advantages of non vascularized graft are significant reduction in pain, early mobilization, easy and technically less demanding procedure, less chance of donor side morbidity, less chance of iatrogenic subtrochentric fractures and shorter operative time.

\section{Conclusion:-}

AVN primarily affacts the young active adults which leads to increase morbidity and functional disability. Our aim of treatment is to delay the progression of the disease. Efficacy of core decompression with cancellous bone 
grafting provide much pain and improve functional abilities. It is safe and effective and easy to perform procedure for modified ficat and arlet stage 1 and stage 2 .

\section{Reference:-}

1. Assouline-Dayan Y, Chang C, Greenspan A, Shoenfeld Y, Gershwin ME (2002) Pathogenesis and Natural History of Osteonecrosis. Semin Arthritis Rheum 32(2): 94-124.

2. 10. Hamilton TW, Goodman SM, Figgie M (2009) Sas Weekly Rounds: Avascular Necrosis. HSSJ 5(2): 99113.

3. Kang P, Pei F, Shen B, Zhou Z, Yang J (2012) Are The Results of Multiple Drilling And Alendronate For Osteonecrosis Of The Femoral Head Better Than Those Of Multiple Drilling? A Pilot Study. Joint Bone Spine 79(1): 67-72.

4. Agarwala S, Shah SB (2011) Ten-Year Follow-Up Of Avascular Necrosis Of Femoral head Treated With Alendronate For 3 years. J Arthroplasty 26(7): 1128-1134.

5. Evans CH (2012) Gene Delivery To Bone. Adv Drug Deliv Rev 64(12): 1331-1340.

6. Camporesi EM, Vezzani G, Bosco G, Mangar D, Bernasek TL (2010) Hyperbaric Oxygen Therapy in Femoral Head Necrosis. J Arthroplasty 25(6 Suppl): 118-123.

7. Camp JF, Colwell CW (1986) Core Decompression of the Femoral Head for Osteonecrosis. J Bone Joint Surg Am 68(9): 1313-1319.

8. R Merle d'Aubigne (1964) Idiopathic necrosis of the femoral head in adults. Ann R CollSurgEngl 34: 143-160.

9. Mont MA, Fairbank AC, Krackow KA, Hungerford DS (1996) Corrective osteotomy for osteonecrosis of the femoral head. J Bone Joint Surg Am 78(7): 1032-1038.

10. Floerkemeier T, Lutz A, Nackenhorst U, Thorey F, Waizy H (2011) Core Decompression And Osteonecrosis Intervention Rod In Osteonecrosis Of The Femoral Head: Clinical Outcome And Finite Element Analysis. IntOrthop 35(10): 1461-1466.

11. Hernigou P, Poignard A, Beaujean F, Rouard H (2005) Percutaneous autologous bone-marrow grafting for nonunions. J Bone Joint Surg Am 87(7): 1430-1437.

12. Hernigou P, Beaujean F (2002) Treatment of osteonecrosis with autologous bone marrow grafting. ClinOrthopRelat Res (405): 14-23.

13. Mont MA, Maar DC, Urquhart MW, et al. Avascular necrosis of the humeral head treated by core decompression. A retrospective review. J Bone Joint Surg Br. 1993;75(5):785-788.

14. Mont MA, Marulanda GA, Seyler TM, et al. Core decompression and nonvascularized bone grafting for the treatment of early stage osteonecrosis of the femoral head. Instr Course Lect. 2007; 56:213-220. 